\title{
MEMÓRIA VIVA: A CONSTRUÇÃO DO INVENTÁRIO PARTICIPATIVO DE BENS PATRIMONIAIS DA VÁRZEA, RECIFE, PE
}

Alexandre Vasconcelos de Moura Farias Filho ${ }^{i}$ Ana Catarina Torres Ramosii Anaís Lara Nascimento Bertrand ${ }^{i}$ Gabriel Interaminense Lucena ${ }^{i}$ Gibran Khalil de Espindola Brandãoi Luanderson Monteiro Ferraz ${ }^{\mathrm{iii}}$ Ricardo Pinto de Medeirosii Rodrigo Nunes de Oliveira ${ }^{i}$ Rosangela Bezerra Alves ${ }^{\text {iv }}$ Thaís Rebeka Santos de Santana ${ }^{i}$

Viviane Cavalcanti de Castroii 
Resumo: O bairro da Várzea, localizado no entorno da UFPE, apresenta-se como um local de grande riqueza e diversidade cultural. Ciente dessa importância, o LEDUP - Laboratório de Educação Patrimonial, do Departamento de Arqueologia da UFPE, elaborou um projeto visando inventariar, com a participação de seus alunos e em conjunto com a comunidade de moradores do bairro, de forma participativa e colaborativa, os bens e as expressões culturais ali presentes. O projeto incorpora as noções de patrimônio a partir da ótica do IPHAN e da própria comunidade, utilizando-se de entrevistas gravadas e filmadas, além do preenchimento de fichas de bens patrimoniais, e terá como finalidade a elaboração de material informativo sobre os bens patrimoniais daquela comunidade, de forma aberta e inclusiva, como forma de retorno e "catalogação" da sua memória cultural. O projeto encontra-se em andamento em fase de elaboração das informações já obtidas. Aqui apresentamos parte desse levantamento. Palavras-Chave: Inventário; Comunidade; Patrimônio.

\footnotetext{
Arqueólogo formado pela Universidade Federal de Pernambuco - UFPE

ii Docente do Departamento de Arqueologia da Universidade Federal de Pernambuco - UFPE.

iii Discente da Universidade Federal de Pernambuco - UFPE

iv Discente do Programa de Pósgraduaçao da Universidade Federal de Pernambuco - UFPE
}

Abstract: The Várzea neighborhood, located around UFPE, presents itself as a place of great wealth and cultural diversity. Aware of this importance, LEDUP - Patrimonial Education Laboratory, of the UFPE Archeology Department, developed a project aiming to inventory, with the participation of its students and jointly with the community of neighborhood residents, in a participatory and collaborative way, the assets and the cultural expressions present there. The project incorporates the notions of heritage from the perspective of IPHAN and the community itself, using recorded and filmed interviews, in addition to filling out property records, and will have the purpose of preparing informative material on the heritage properties of that community, in an open and inclusive way, as a way of returning and "cataloging" their cultural memory. The project is in progress and the information already obtained is being prepared. Here we present part of that survey. Key Words: Inventory; Comunity; Patrimony. 


\section{Introdução}

O Inventário Participativo é uma ferramenta de Educação Patrimonial que visa garantir a continuidade e a proteção das referências culturais materiais ou imateriais de um povo, apresentando-se como um exercício de cidadania e participação social. A atividade enxerga a população como protagonista para inventariar, descrever, classificar e definir o que considera como patrimônio cultural, buscando mobilizar e sensibilizar a comunidade para a importância de seu patrimônio (Iphan, 2016).

Os bens catalogados no Inventário são entendidos como patrimônio a partir do momento em que eles se mostram muito presentes na história de um grupo, sendo transmitidas de geração em geração. São referências que ligam as pessoas aos seus antepassados, àqueles que viveram muito antes delas; são referências que se quer transmitir as próximas gerações. O patrimônio cultural faz parte da vida das pessoas de forma profunda (Iphan, 2016).

Para a elaboração de um Inventário Participativo, é necessário envolver o máximo possível de pessoas; devem ser entendidos os conceitos e categorias do inventário por todos que o produzem; e as atividades do processo devem ser organizadas previamente.

Neste projeto, os bens patrimoniais inventariados são pertencentes ao bairro da Várzea, cidade do Recife, e que, até os dias atuais, estão guardados na memória dos moradores.

\section{O Inventário Participativo no Bairro da Várzea}

A Várzea foi sede de uma pequena povoação do século XVI, originária do Engenho Santo Antônio que, junto com o São João e o do Meio, faziam parte dos engenhos que existiam na região da Várzea do Capibaribe. Foi uma das áreas mais importantes na produção açucareira durante os séculos XVI, XVII e XVIII (Silva, 2019).

Atualmente, é o segundo maior bairro do Recife em extensão e possui um rico patrimônio cultural que engloba, além de antigos casarios e engenhos, igrejas e diversas manifestações e formas de expressão, um trecho do "antigo caminho da Várzea", que ligava os engenhos que tornavam, no início do período colonial, a Várzea do rio Capibaribe a área de maior produção açucareira da Capitania de Pernambuco. 
A área definida para atuação da equipe foi escolhida a partir do que se considerava a Várzea até o início do século $X X$, o que demandou pesquisas históricas para a demarcação de um polígono e a escolha das ruas. Um dos critérios considerados foi a presença de casarões históricos, monumentos ou áreas com potencial arqueológico, além dos locais mais recorrentes na fala dos moradores, obtidos através das entrevistas.

O projeto tem como propósito inventariar, com a participação de estudantes de arqueologia da Universidade Federal de Pernambuco (UFPE) em conjunto com a comunidade de moradores do bairro, de forma participativa e colaborativa, os bens e as expressões culturais presentes no bairro da Várzea, no qual a universidade está localizada.

A metodologia básica do trabalho dividiu-se em três etapas: pré-campo, campo, e pós-campo. No pré-campo, foram realizadas leituras do material base publicado pelo Iphan, "Educação Patrimonial: Inventários Participativos" (Iphan, 2016) e "Educação Patrimonial: Histórico, conceitos e processos" (Iphan, 2014), para conhecimento prévio das atividades a serem realizadas em campo e início do planejamento dos trabalhos e materiais utilizados.

Foram também elaboradas, na primeira etapa, as fichas de bens a serem catalogados, adaptadas para os bens da Várzea; o roteiro base, contendo perguntas gerais que permitiram direcionar o entrevistado; e o termo de livre consentimento, necessário para que os registros de imagem e voz pudessem ser utilizados no projeto.

Na etapa de campo, foram realizadas as entrevistas com os moradores da Várzea, a partir do roteiro base. As entrevistas aconteceram por meio de uma conversa informal, onde foram pontuados pelos moradores, a partir de sua vivência, os bens de maior importância da Várzea. Durante esta etapa também foram efetuados registros imagéticos dos bens citados, de modo a criar um acervo para o preenchimento das fichas de bens.

No pós-campo, os dados levantados em campo foram analisados e compilados, dando origem a um quadro com a recorrência dos bens citados nas entrevistas, e foi criado um acervo audiovisual dos moradores e realizado o preenchimento de fichas dos bens que farão parte do Inventário Participativo da Várzea. 
FARIAS FILHO,A.V.de M.;RAMOS, A.C.T.;BERTRAND, A.L.N.; LUCENA, G.I.;BRANDÃO, G.K.de.E.; FERRAZ, L.M. ; MEDEIROS, R.P.de; OLIVEIRA, R.N. de.; ALVES, R.B.; SANTANA, T.R.S.de; CASTRO,V.C.DE

\section{Primeiros Resultados}

Próximo de completar um ano de projeto, o Inventário Participativo da Várzea apresenta os seguintes resultados: foram efetuadas 12 entrevistas, bem como compilados, aproximadamente, 48 bens culturais materiais e imateriais da Várzea divididos com base na metodologia do Inventário Participativo em: Celebrações, Expressões culturais, Lugares, Objetos e Saberes(Quadro 1). Foram preenchidas, até o momento, 19 fichas de bens culturais.

Quadro 1: Relação de bens culturais levantados

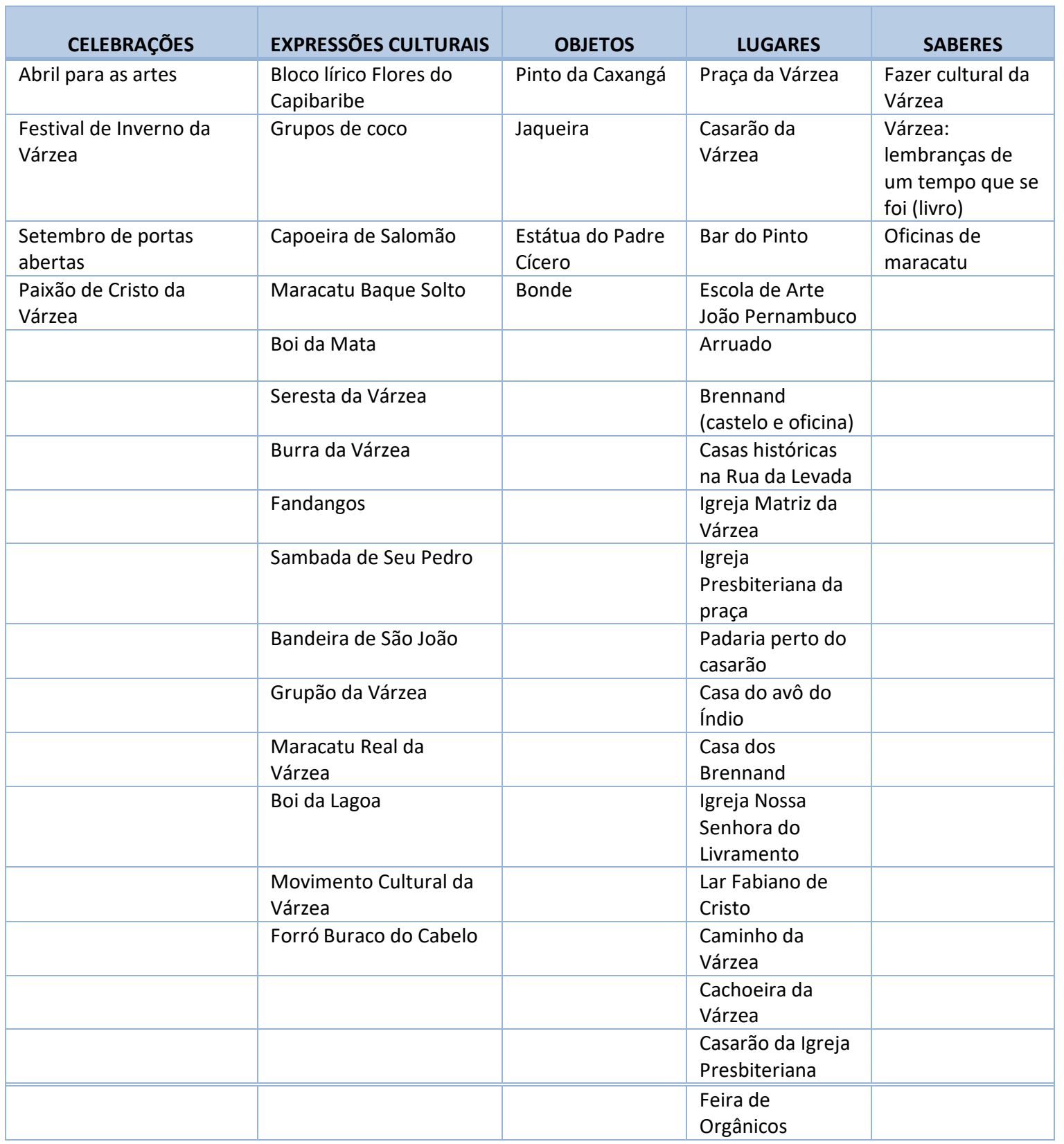


Dentro da ficha de cada bem além das informações que constam nas entrevistas, foram realizadas pesquisas históricas e bibliográficas, assim como fotografias e, quando necessário, as medições dos bens construídos.

Dentre os bens levantados e mais citados pela comunidade foram selecionados sete (7), apresentados abaixo:

\section{Praça da Várzea}

É o centro das manifestações culturais do bairro, que recebe ensaios de maracatu, festejos juninos, troças carnavalescas, festivais de arte, além de atividades esportivas e recreativas. A praça (Figura 1) passou por várias modificações ao longo dos séculos, uma dessas teve a assinatura de Burle Marx.



Figura 1: Praça da Várzea. Fonte: Alexandre Filho, 2019.

\section{Maracatu Real da Várzea}

Grupo de maracatu de baque virado e ritmos afro-brasileiros criado na Várzea (Figura 2). As apresentações acontecem na Praça da Várzea todos os sábados, onde também são oferecidas oficinas de música e danças ministradas pelo Mestre Abissal. 


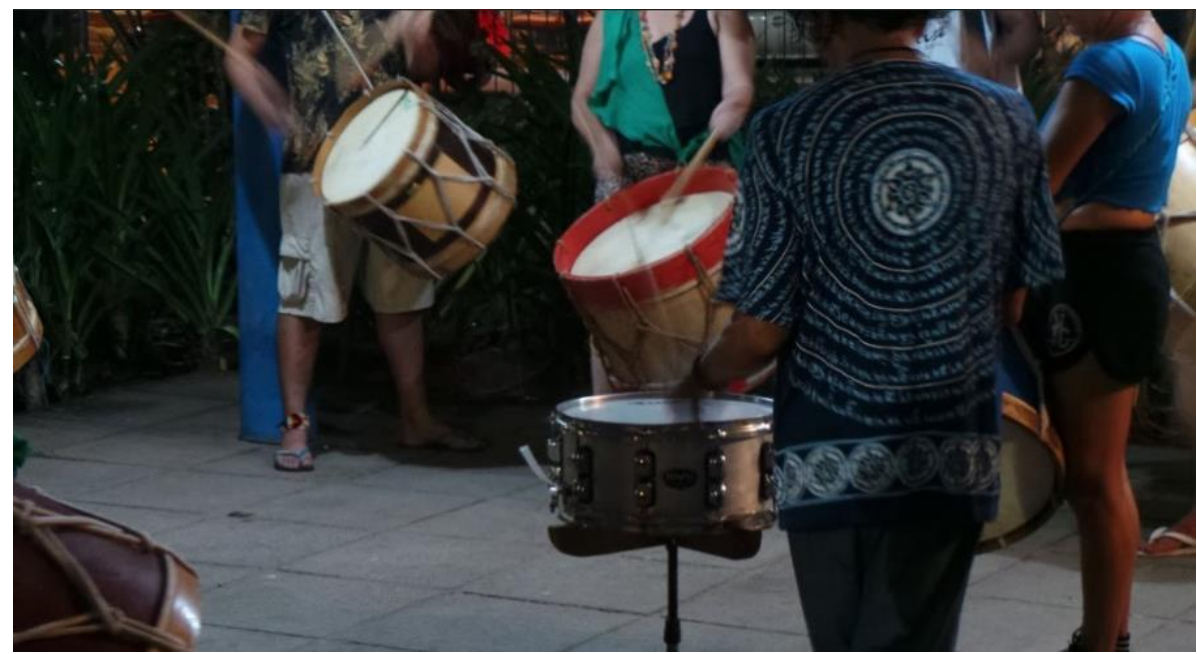

Figura 2: Instrumentos de percussão utilizados no ensaio do Maracatu. Fonte: Luanderson Monteiro, 2019.

\section{Igreja Matriz da Várzea}

Igreja dedicada a Nossa Senhora do Rosário (Figura 3), fundada no final do século XVI, retratada por Frans Post e palco de várias manifestações artísticas e políticas. É o lugar onde foi sepultado Antônio Filipe Camarão em 1645. Ela já foi objeto de trabalho arqueológico efetuado por arqueólogos da UFPE, cuja parede lateral esquerda guarda testemunhos de tal intervenção (Figura 4).

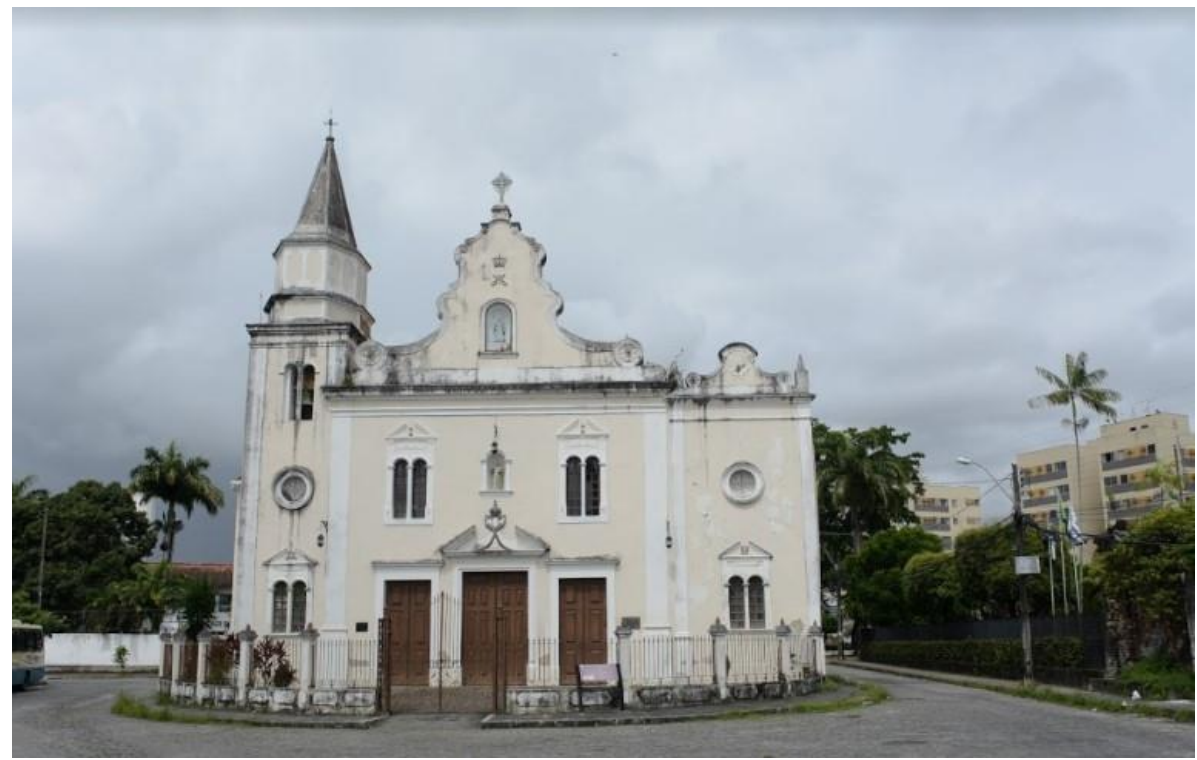

Figura 3: Fachada da Igreja Matriz da Várzea. Fonte: Alexandre Filho, 2019. 


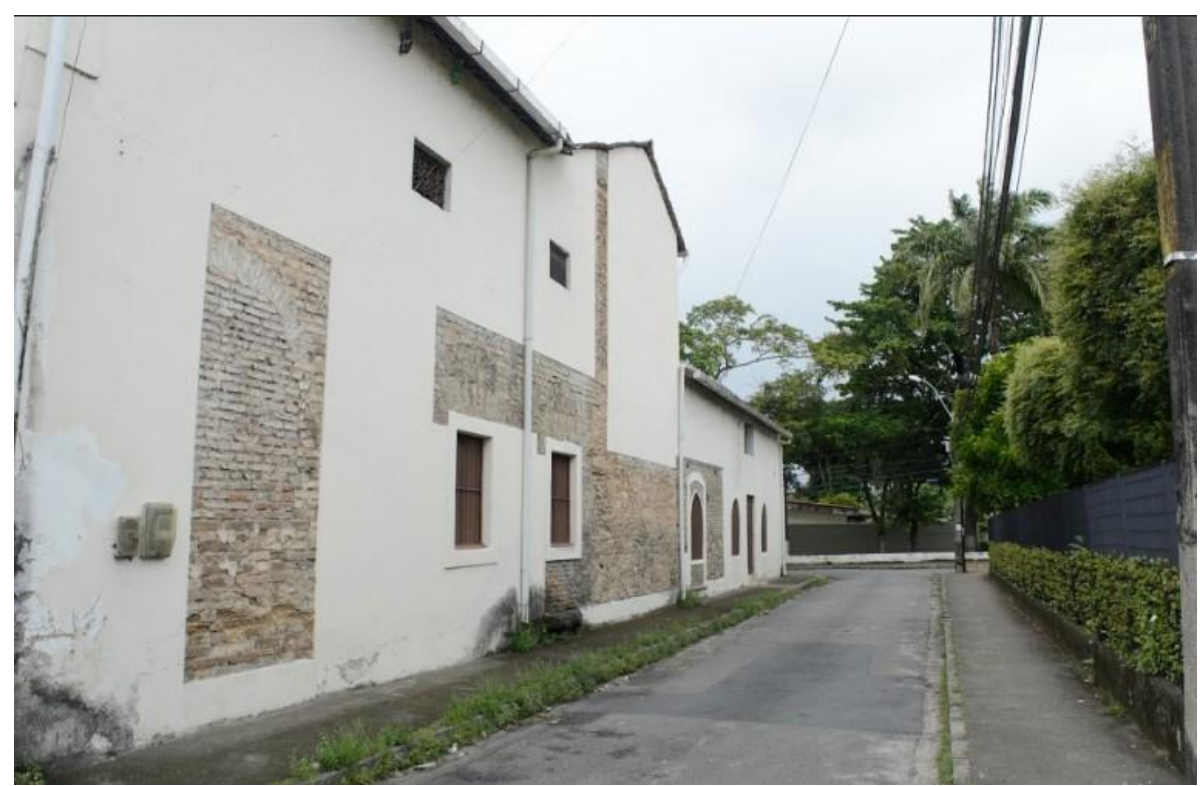

Figura 4: Vista lateral direita da Igreja Matriz da Várzea. Fonte: Alexandre Filho, 2019.

\section{Burra da Várzea}

Brincadeira popular da Várzea, criada em 1962, pelo brincante Arlindo Cavalcanti Cabral, popularmente conhecido como "Seu Dida". A concentração acontece geralmente na Praça da Várzea, ponto de partida do cortejo que segue pelo bairro, junto com os brincantes em datas comemorativas (Figura 5).

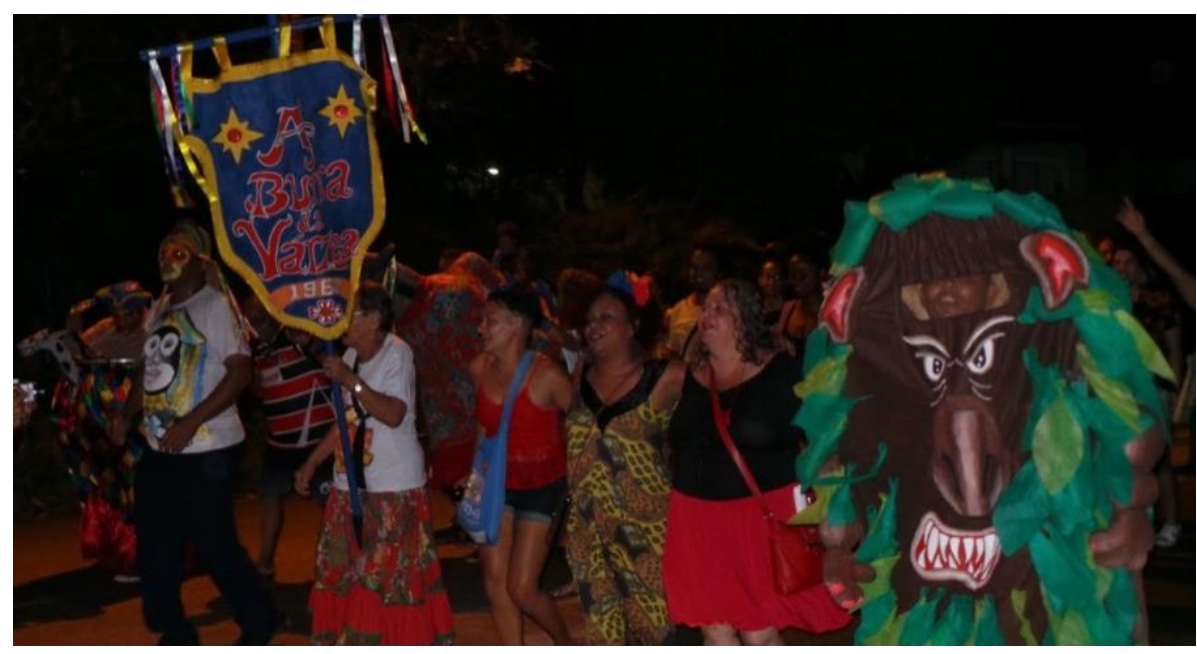

Figura 5: Brincantes no cortejo da Burra da Várzea. Fonte: Rodrigo Oliveira, 2019. 
FARIAS FILHO,A.V.de M.;RAMOS, A.C.T.;BERTRAND, A.L.N.; LUCENA, G.I.;BRANDÃO, G.K.de.E.; FERRAZ, L.M. ; MEDEIROS, R.P.de; OLIVEIRA, R.N. de.; ALVES, R.B.; SANTANA, T.R.S.de; CASTRO,V.C.DE

\section{Escola de Artes João Pernambuco}

Fundada na década de 1970, a escola (Figura 6) funciona em um imóvel histórico e oferece cursos gratuitos de dança, teatro, música e artes visuais.

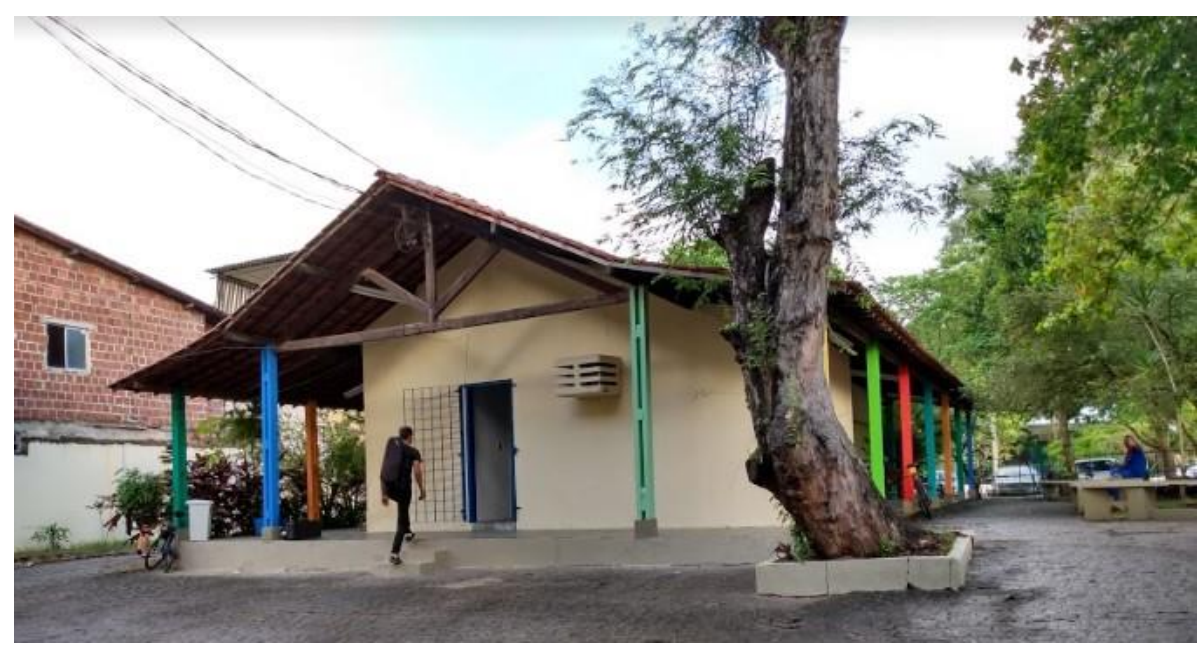

Figura 6: Vista posterior do casarão histórico onde funciona a Escola João Pernambuco. Fonte: Rodrigo Oliveira, 2019.

\section{Casarão da Várzea}

Construído em 1905, abrigou o Hospital Magitot, primeiro Centro Odontológico da América do Sul (Silva Sobrinho, 2012). Abandonado por décadas (Figuras 7 e 8), em 2016 foi ocupado para realização de atividades culturais do bairro através do movimento Salve o Casarão da Várzea.

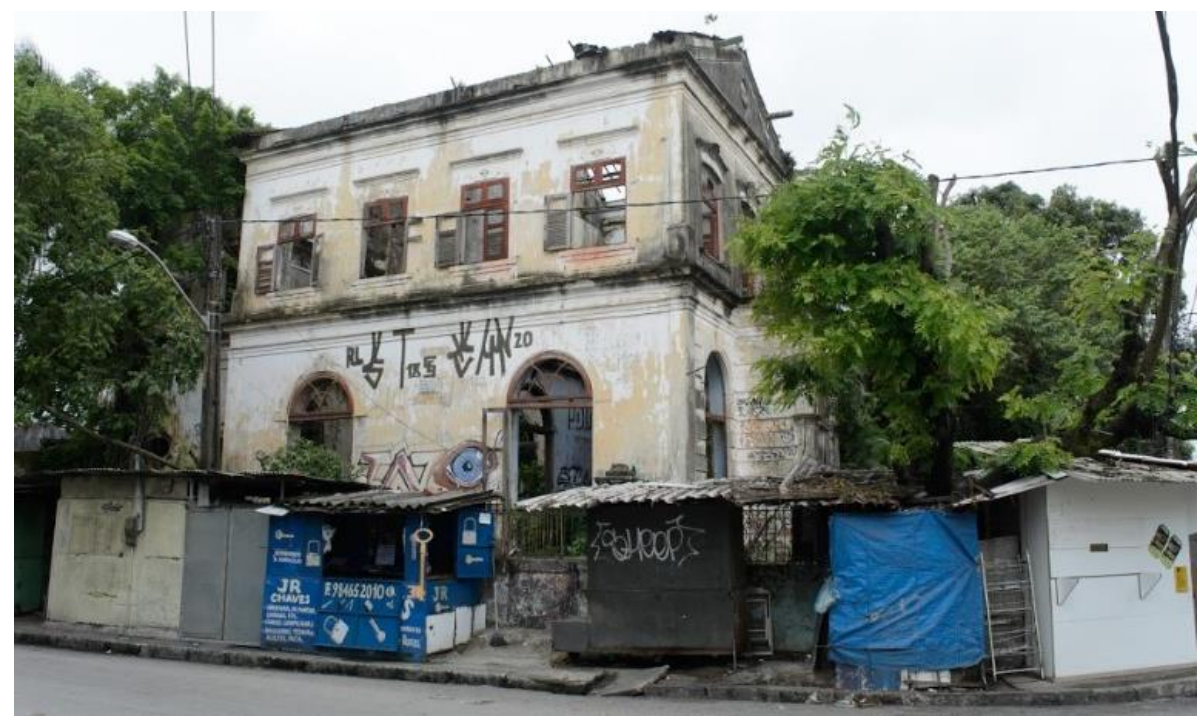

Figura 7: Lateral direita do casarão da Várzea. Fonte: Alexandre Filho, 2019. 


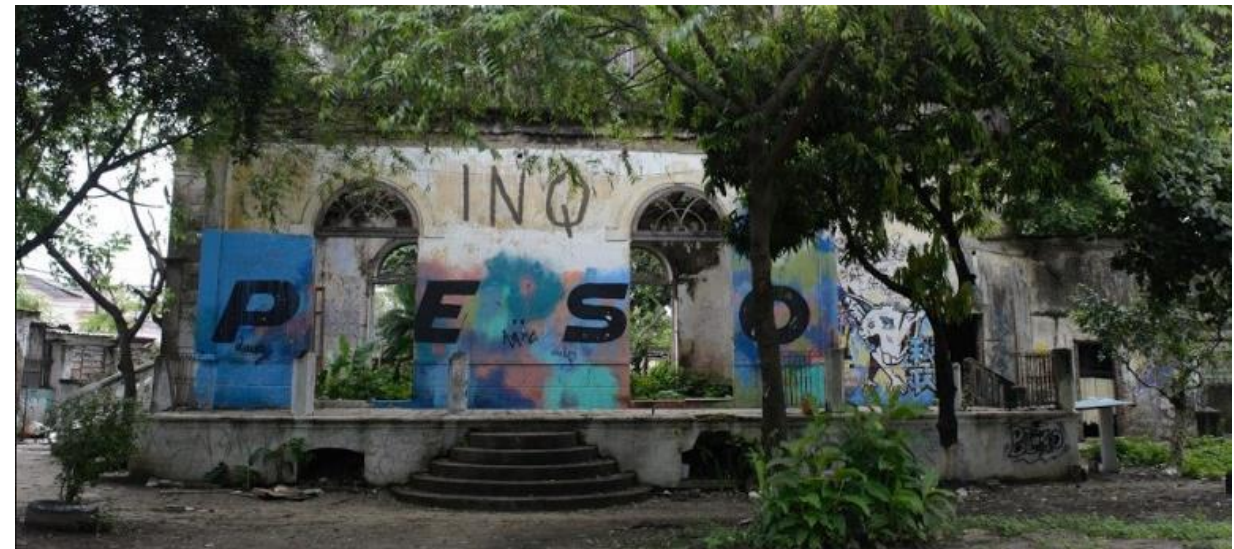

Figura 8: Lateral direita do casarão da Várzea. Fonte: Alexandre Filho, 2019.

\section{Arruado}

O Arruado (Figura 9) é uma comunidade que está localizada dentro da Universidade Federal de Pernambuco. O espaço era lugar de encontro para manifestações artísticas diversas, é referência cultural da Várzea, sendo inclusive, o local onde várias atividades do Grupão da Várzea aconteciam. Ela possui ligação com o antigo Engenho do Meio, onde hoje há uma área de pesquisa arqueológica.

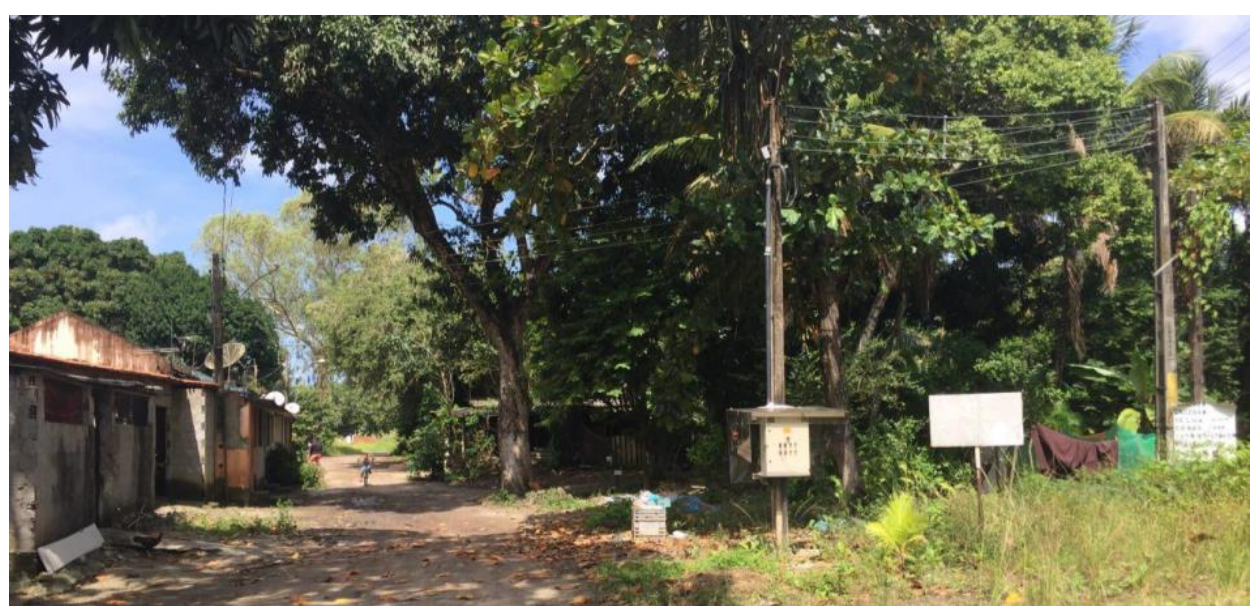

Figura 9: Comunidade do Arruado. Fonte: Anaís Bertrand, 2019.

\section{Considerações Finais}

A partir do contato com os bens e com a comunidade, foi possível notar de forma ainda mais próxima, a influência que a Arqueologia pode exercer dentro da comunidade no estímulo à valorização e permanência dos bens patrimoniais dentro daqueles espaços. Como por exemplo, o resultado do trabalho de Educação Patrimonial realizado na comunidade do 
Arruado em conjunto com alunos e professores do curso de Arqueologia (RAMOS, CASTRO, MEDEIROS, 2019).

Durante todo o percurso de realização do projeto, a equipe se deparou com outros trabalhos de divulgação e promoção cultural envolvendo o bairro da Várzea, tais como os desenvolvidos pela "Burra da Várzea" e pela "Escola de Arte João Pernambucano", o que deixa evidente a importância artística e cultural que o bairro possui.

Neste contexto, o bairro da Várzea desperta interesse pelos bens, pelas manifestações artísticas que se destacam pela permanência, bem como pelos moradores que também guardam, em si, memórias, saberes, lembranças de um lugar que foi - e ainda é - um dos melhores lugares dentro do Recife para se viver.

\section{Agradecimentos}

Especialmente para aqueles que fizeram e fazem esse trabalho junto com a equipe, para aqueles que são, à sua maneira, patrimônio da Várzea. Congratulações a cada um dos moradores que dispuseram de seu tempo para relatar um pouco de suas vivências no bairro.

\section{Referências}

CAVALCANTI, C. B. 2013. O Recife e os seus bairros. 6 ed. Camaragibe. CCS Gráfica e Editora.

INSTITUTO DO PATRIMÔNIO HISTÓRICO E ARTÍSTICO NACIONAL 2014. Educação Patrimonial: Histórico, conceitos e processos. Brasília, IPHAN.

INSTITUTO DO PATRIMÔNIO HISTÓRICO E ARTÍSTICO NACIONAL, 2016. Educação Patrimonial: Inventários Participativos. Manual de Aplicação. Brasília, IPHAN.

RAMOS, A. C. P. T.; CASTRO, V. M C.; MEDEIROS, R. P. 2019. Comunidade do Arruado do antigo Engenho do Meio, universidade e ações educativas. In: XX Congresso da SAB: Memória, Patrimônio Cultural e Direitos Humanos, 2019, Pelotas. Anais do XX Congresso da SAB, p. 1-5.

SILVA, L. D. 2019. Várzea (bairro, Recife). Pesquisa Escolar Online, Fundação Joaquim Nabuco, Recife. Disponível em: <http://basilio.fundaj.gov.br/pesquisaescolar/>. Acesso em 27 de setembro, 2019.

SILVA SOBRINHO, M. F. 2012. Várzea: lembranças de um tempo que se foi. Recife: Ed. do Autor. 